\title{
Thermoregulatory Behavior of Red Sea Urchin Strongylocentrotus Fran- ciscanus (Agassiz, 1863) and Purple Sea Urchin Strongylocentrotus Purpu- ratus (Stimpson, 1857) (Echinodermata: Echinoidea)
}

\author{
Alfredo Salas ${ }^{1}$, Fernando Diaz ${ }^{2 *}$, Ana Denisse $\mathrm{Re}^{2}$, Marco Gonzalez ${ }^{1}$ and Clara Galindo ${ }^{3}$ \\ ${ }^{1}$ Instituto de Investigaciones Oceanológicas. Universidad Autónoma de Baja California. Kilometro 103 Carretera Ti- \\ juana-Ensenada, Ensenada Baja California. México \\ ${ }^{2}$ Laboratorio de Ecofisiología de Organismos Acuáticos. Departamento de Biotecnología Marina, Centro de Investiga- \\ ción Científica y de Educación Superior de Ensenada (CICESE), Carretera Ensenada-Tijuana \# 3918, Ensenada Baja \\ California, México \\ ${ }^{3}$ Laboratorio de Genómica Funcional. Departamento de Biotecnología Marina, Centro de Investigación Científica y de \\ Educación Superior de Ensenada (CICESE), Carretera Ensenada-Tijuana \# 3918, Ensenada Baja California, México
}

\begin{abstract}
Thermoregulatory behavior of red sea urchin Strongylocentrotus franciscanus and purple sea urchin S. purpuratus was determined in a horizontal thermal gradient. The preferred temperature select by the red sea urchin was $17.5 \pm$ $0.3^{\circ} \mathrm{C}$ during the diurnal cycle and $16.8 \pm 0.4{ }^{\circ} \mathrm{C}$ for the night. The purple sea urchin preferred temperature during daytime of $18.8 \pm 0.2^{\circ} \mathrm{C}$ and night was $17.4 \pm 0.3^{\circ} \mathrm{C}$. For both species of sea urchin preferendum between day and night cycles were different $(\mathrm{P}<0.05)$, the purple sea urchin preferred higher temperatures that red urchin, suggesting that $S$. purpuratus use thermoregulatory behavior as a mechanism of environmental segregation to avoid competition for space and food with red sea urchin.
\end{abstract}

Keywords: Preferred temperature, red sea urchin, purple sea urchin.

\section{INTRODUCTION}

Environmental temperature plays a vital role in determining when and where aquatic species may survive and prosper, such as ectotherms. Laboratory studies have shown that variations in temperature have an important effect on the physiological and biochemical rates at the level of the organism and affect its ability to survive, growth, and reproduction [1-3]. Temperature is a controlling and directive factor of the activity of aquatic species and therefore mobile species, such as sea urchins, exhibit different behavioral responses including thermal habitat selection and avoid lethal temperatures $[4,5]$. For many aquatic species a preferred temperature is a primary function of its recent thermal history or state of thermal acclimation [6].

Ectotherms have a capacity to cope with the changes in temperature that occur in the environment by selecting favorable habitats for using behavioural responses [4]. The preferred temperature represents a thermal interval in which the processes that control activity are not affected and their efficiency is therefore increased and optimized [7-9]. Fry [10] defines the final preferendum as the temperature around

\footnotetext{
*Address correspondence to this author at the Departamento de Biotecnología Marina Centro de Investigación Científica y de Educación Superior de Ensenada (CICESE), Carretera Ensenada-Tijuana \# 3918, Ensenada Baja California, México. (CICESE); Tel: 01152-6461750500;

Fax: 01152-6461750569; E-mail: fdiaz@cicese.mx
}

which all individuals (of a given species) can congregate, regardless to previous thermal history before being placed in the gradient $[11,12]$. Jobling and Kellog $[13,14]$ have shown that organisms select temperatures in proportion to quantity of metabolic energy necessary for maximize different biological processes such as metabolism, swimming speed, growth. Body temperature (Tb) is the most important ecophysiological variable that affects the function of ectotherms. Virtually all aspects of behavior and physiology of ectotherms are sensitive to $\mathrm{Tb}[15,16]$. The thermoregulatory behaviour is used by ectotherms to reduce the spatial and temporal impact of environmental temperature under $\mathrm{Tb}$ [15]. Thermal preference studies conducted in the laboratory propose a vital link in the environmental, physiological, and adaptive behavioral tactics used by aquatic organisms [17].

In the state of Baja California two types of sea urchins are commercially important, red Strongylocentrotus franciscanus (Agassiz 1863) and purple Strongylocentrotus purpuratus (Stimpson 1857). Red sea urchins are distributed from Alaska to Isla Cedros in Baja California México; this species is found between the intertidal zone and 50 meters in depth on rocky substrates $[18,19]$. Purple sea urchins Strongylocentrotus purpuratus have a wide biogeographic distribution that extend from southern Alaska to central Baja California México, this species are exposed to a wide range of environmental temperatures from 4 to $20^{\circ} \mathrm{C}$ [20]. Coastal fishing represents an important factor in Baja California, providing 2,000 people with jobs directly and producing 7 million 
dollars per season in sea urchin gonad production. Red sea urchin populations have been subject to commercial exploitation since the seventies; according to [21] this resource is considered overexploited. This study is the first to evaluate the thermal preference of adult red sea urchins Strongylocentrotus franciscanus and purple sea urchins $S$. purpuratus to obtain an estimate of the optimum preferred temperature for growth and reproduction and thus evaluating the ability of the these organisms to adapt to different thermal regiments along the coast of Baja California and the potential impact of climate change.

\section{MATERIAL AND METHODOLOGY}

Strongylocentrotus franciscanus and S. purpuratus (with a range of $2.9-8.6 \mathrm{~cm}$ and $1.0-8.6 \mathrm{~cm}$ in test diameter) were collected by scuba diving at a depth of 5 to 10 meters at Campo Kennedy in Punta Banda, Baja California, México ( $31^{\circ} 42.16^{\prime}$ Lat. N; $116^{\circ} 40.9^{\prime}$ Long. W.). The organisms were kept 21 days in a laboratory in 200L reservoirs with a continuous water replacement system, with a salinity of $35 \%$, and a temperature of $16 \pm 1^{\circ} \mathrm{C}$, which were the conditions registered during the collection. The red and purple sea urchins were fed fronds of Macrocystis pyrifera Linnaeus (kelp) in accordance with [19].

Forty-eight hours prior to starting the sea urchins were marked with plastic tags with nylon string on the spines for individual identification. The preferred temperature experiments for both species of sea urchins were performed in a gradient as described by [22]. A Neslab Thermoregulator (model HX 150) was connected at one end of the gradient to cool the water. A 1000 watt heater was placed at the opposite side of the gradient, which was connected to a temperature controller (Moeller CI-K3-125-M) to warm the water, generating a stable gradient of $10^{\circ}$ to $30^{\circ} \mathrm{C},\left(y=6.20+1.60 x, r^{2}=\right.$ 0.98 where $x=$ segments of the gradient, $y=$ temperature in each segment of the gradient). Twenty aeration stones were placed along the gradient to maintain a dissolved oxygen concentration of 5.8- 7.2 $\mathrm{mg} \mathrm{L}^{-1}$, thus eliminating the stratification effect of the water column. The depth of the water column in the gradient was $9 \mathrm{~cm}$ and to maintain a good quality of water the replacement rate was $10.0-12.0 \mathrm{~L} \mathrm{~h}^{-1}$.

To determine the preferred temperature of the sea urchins the gravitational method described by [23] was used. Five sea urchins, of both species marked with individual labels, were introduced to the segment in the gradient where the water temperature was the same as temperature of acclimatization from where they came from. For each sea urchin 10 repetitions were performed $(N=50)$. The sea urchins were not fed 24h prior to the testing period to prevent interference due to diet $[24,25]$. During the day they were exposed to high light intensity of $0.55 \times 10^{15}$ quanta $\sec ^{-1} \mathrm{~cm}^{-2}$ and $0.10 \mathrm{x}$ $10^{15}$ quanta $\mathrm{sec}^{1} \mathrm{~cm}^{-2}$ at night. Observations made on the number of sea urchins in the gradient segments were made by a mirror at a $45^{\circ}$ angle and were recorded every hour of a 24h period. Temperature was also measured with digital thermometers, which were distributed equally along the gradient by matching each of the virtual segments.

Subsequent to the calculations of normality and homoscedasticity of the data the nonparametric test was applied by Mann-Whitney to determine differences in preferred tem- perature in both species of sea urchins exposed to the day and night light cycle [26]. To contrast the differences in the day and night preferendum of the sea urchin $S$. franciscanus and $S$. purpuratus the nonparametric test was applied by Kruskall-Wallis [26]. The data on the preferred temperature of both species of sea urchin were processed using exploratory data analysis and presented in parallel box plot [27].

\section{RESULTS}

Red sea urchins, Strongylocentrotus franciscanus, that were exposed to a day and night cycle in the gradient had a preferred temperature range of $17.5 \pm 0.3^{\circ} \mathrm{C}$ during the day and $16.8 \pm 0.4{ }^{\circ} \mathrm{C}$ at night (Fig. 1). Purple sea urchins, $S$. purpuratus, had a preferred temperature range of $18.8 \pm 0.2$ ${ }^{\circ} \mathrm{C}$ during the day and $17.4 \pm 0.3^{\circ} \mathrm{C}$ at night (Fig. 2). The interpreferenda interval transition for the red sea urchin was $0.7^{\circ} \mathrm{C}$ and as for the purple sea urchin $1.4^{\circ} \mathrm{C}$, where the sea urchins began to displacement to move toward favorable physiological temperatures. There were significant differences in the preferred temperature in both species of sea urchin in the day and night cycle $(\mathrm{P}<0.05)$ (Figs. 1 and 2 ). When comparing through the nonparametric test of KruskallWallis the day and night preferred temperature of the red sea urchins with obtained for the purple sea urchins significant differences were found $(\mathrm{P}<0.05)$.

\section{DISCUSSION}

The temperature preferendum of both sea urchins were significantly different between the day and night cycles. In the case of fresh water snail Helisoma trivolis, Say [28] found a diel rhythm of preferred temperature at $17-18{ }^{\circ} \mathrm{C}$ during the day cycle and $21-22^{\circ} \mathrm{C}$ during the night cycle. For the sea snail Megastrea (Lithopoma) undosa Wood [6] obtained a diel rhythm of preferred temperature. In other aquatic species such as Amia calva Linnaeus, Procambarus spiculifer Le Conte, Procambarus clarkii Girad [29-31] have also reported diel rhythms of preferred temperatures between both day and night cycles. This behavior can be explained by the hypothesis of bioenergetics proposed by [32] who suggests that the diel rhythms of preferred temperatures between the day and night favor the daily metabolic balance in aquatic ectotherms, this mechanism can be used by many organisms to preserve energy when food is limited in its habitat.

The preferred temperatures, for both species of sea urchin, are probable to be those that provide the greatest field of activity, and therefore a greater amount of energy available can be channeled to other functions such as scope for activity according to [10], reproduction, survival, and growth [12]. It has been reported by $[33,34]$ that the optimum interval of temperatures for the feeding of $S$. franciscanus was 15.7 to $17.1^{\circ} \mathrm{C}$. As for S. purpuratus [35] obtained that the embryonic development was carried out normally between the intervals of 13 to $20^{\circ} \mathrm{C}$. Ulbricht [36] reported that the temperature coefficient $\left(Q_{10}\right)$, for the red sea urchin $S$. franciscanus was 1.19 in a temperature interval of 15 to $18^{\circ} \mathrm{C}$ and 0.88 for $S$. purpuratus in a temperature interval of 18 to $21^{\circ} \mathrm{C}$, which indicated that within these temperature interval the organism had a better adaptive responses to maintain homeostasis. Stated by $[37,38]$ that the point where the $Q_{10}$ 
decreases in relation to acclimation temperature corresponds to the optimum temperature for growth and reproduction. A decrease in the value of $Q_{10}$ indicated that the metabolism of the organisms is reduced and therefore there was a greater amount of energy available for the organism to allocate for different processes. These temperature ranges reported for different physiological processes in both species of sea urchin coincide with the thermal preferendum values stated by this paper for red and purple sea urchin. According to [13] the analysis of data on thermal preference in different aquatic organisms indicates that the preferred temperature may be used as a fast method to determine the temperature required to promote maximum growth in both species of sea urchin.

Purple sea urchins S. purpuratus preferred higher temperatures than the red sea urchins $S$. franciscanus. Giattina et al.[5] suggested four hypotheses to unify the concepts in the study of behavioral thermoregulation in aquatic organ-

\section{Red Sea Urchin}

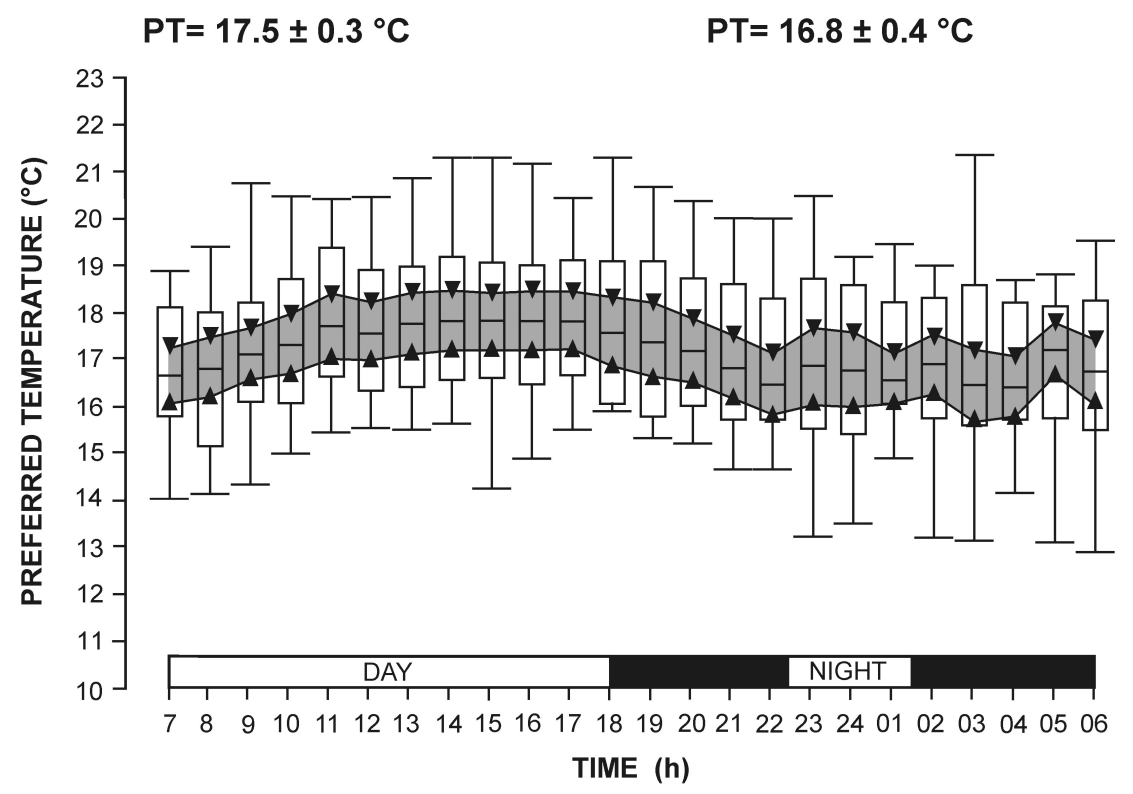

Fig. (1). Thermoregulatory behaviour of red sea urchin Strongylocentrotus franciscanus in a day-night cycle. The shadow zone bordered by triangles represents the $95 \%$ confidence interval of the median. The bars include $50 \%$ of the distribution and the vertical lines represent the quartiles.

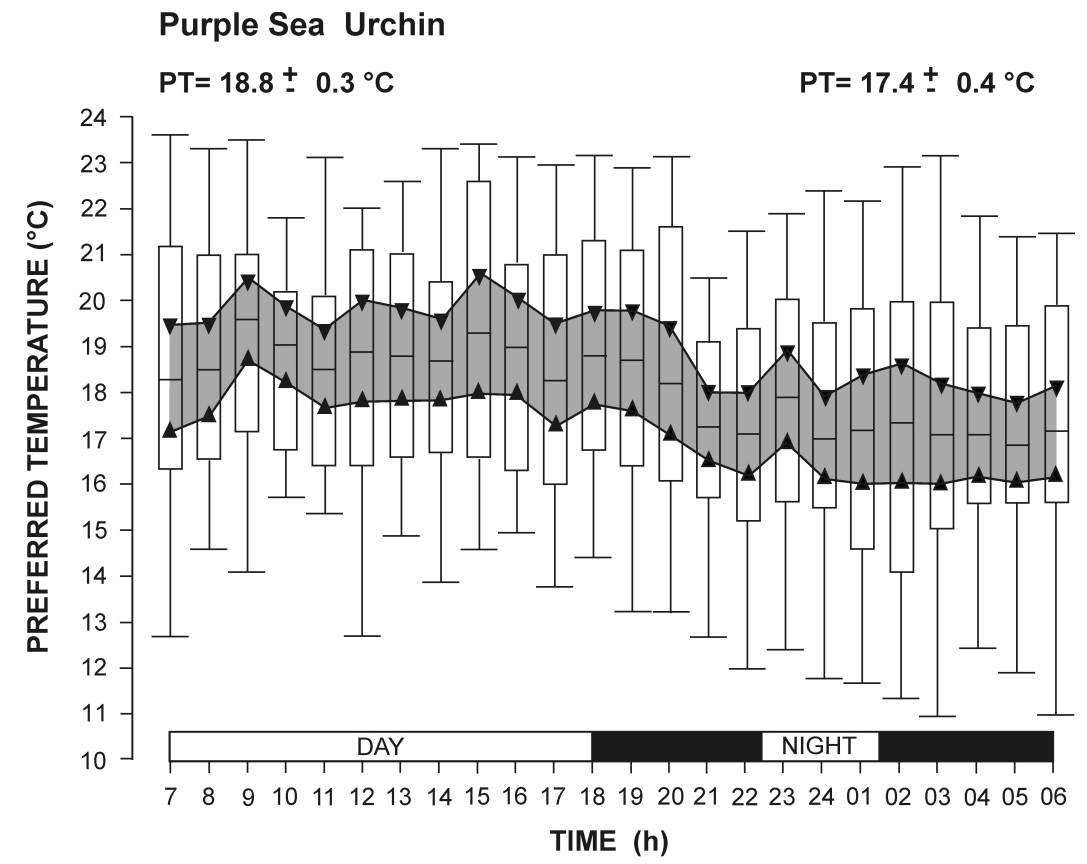

Fig. (2). Thermoregulatory behaviour of purple sea urchin Strongylocentrotus purpuratus in a day-night cycle. The shadow zone bordered by triangles represents the $95 \%$ confidence interval of the median. The bars include $50 \%$ of the distribution and the vertical lines represent the quartiles. 
isms: 1) the final thermal preferendum is a species-specific response to a temperature gradient but can be modified by non-thermal factors such as age, food availability, seasonality, and pathological condition; 2) partitioning of the habitat by thermoregulatory behavior is a measure of segregation both intra and interspecific that permits the reduction in cannibalism and competition; 3) the preferred temperature can reflect thermal optimum for certain biological processes and 4) generally aquatic organisms avoid thermal extremes before they turn lethal. Pearse [39] mention that the purple sea urchin competes with abalone and red sea urchins for space and food. Therefore the purple sea urchin according to what was stated by [5] use thermoregulatory behavior for environmental segregation to avoid competition for space and food against the red sea urchins which coincides with the second hypothesis and as mentioned by [40] that the purple sea urchins are distributed in the intertidal habitat, in contrast to juvenile red sea urchins which do it in the sub tidal. An interval of physical and biological factors such as preferred temperature, competition, and dietary preference vary in species and can lead to separation of the niche as reported in this paper for both species of sea urchin by thermoregulatory behavior.

Behavioral responses to temperature have an adaptive value physiologically and ecologically for the species. We have demonstrated that sea urchins, like arthropods and vertebrates, may have thermoregulatory behavior when they are placed in a temperature gradient. The distribution of animals on the temperature in their natural habitat may be the result of an active thermoregulatory behavior and not merely due to passive processes of differential survival.

This information is vital to determine the suitability of different areas for the cultivation of species such as sea urchins, meet environmental requirements to keep in captivity, and understand its distribution in addition to providing useful results to determine the effects of climate change on these species [20].

\section{CONFLICTS OF INTEREST}

The authors confirm that this article content has no conflicts of interest.

\section{ACKNOWLEDGEMENTS}

We thank Jose M. Dominguez and Francisco Javier Ponce from the Drawing Department of CICESE for preparing the figures.

\section{REFERENCES}

[1] Thomas CW, Crear BJ, Hart PR. The effect of temperature on survival, growth, feeding and metabolic activity of the southern rock lobster Jasus edwardsii. Aquaculture 2000; 185: 73-84.

[2] Hochachka PW, Somero GN. Biochemical adaptations: Mechanisms and process in physiological evolution. Oxford University Press: New York 2002; p. 466.

[3] Kordas RL, Harley CDG, O'Connor MI. Community ecology in a warming world: The influence of temperature on interspecific interactions in marine systems. J Exp Mar Biol Mar Ecol 2011; 400: 218-26.

[4] Reynolds WW. Perspective an introduction to the symposium: thermoregulation in ectotherms. Am Zool 1979; 19: 193-4.
[5] Giattina JR, Garton RR. Graphical model of thermoregulatory behavior by fishes with a new measure of eurythermality. Can J Aquat Sci 1982; 39: 524-28.

[6] Díaz F, Salas A, Re AD, Gonzalez M, Reyes I. Thermal preference and tolerance of Megastrea (Lithopoma) undosa (Wood 1828). J Therm Biol 2011; 36: 34-7.

[7] Kelsch SW, Neil WH. Temperature preference versus acclimation in fishes; selecting for changing metabolic optima. Trans Am Fish Soc 1990; 119: 601-10.

[8] Hecht T. Behavioural thermoregulation of the abalone Haliotis midae, and the implications for intensive culture. Aquaculture 1994; 26: 171-81.

[9] Díaz F, Del Rio-Portilla M, Sierra E, Aguilar M, Re A. Preferred temperature and critical thermal maxima of red abalone Haliotis rufescens. J Therm Biol 2000; 25: 257-61.

[10] Fry FEJ. Effects of the environment on animal activity. University of Toronto Studies in Biology Series 55. Publ Ontario Fish Res. Lab 1947; 68: 1-62.

[11] Bryan JD, Kelsch SW, Neill WH. The maximum power principle in behavioral thermoregulation by fishes. Trans Am Fish Soc 1990; 119: 611-21.

[12] Kelsch SW. Temperature selection and performance by bluegills; evidence for selection in response to available power. Trans Am Fish Soc 1996; 125: 948-55.

[13] Jobling M. Temperature tolerance and the final preferendum-rapid methods for the assessment of optimum temperatures. J Fish Biol 1981; 19: 439-55.

[14] Kellog RL, Gift JJ. Relationship between optimum temperature for growth and preferred temperature for the young four fish species. Trans Am Fish Soc 1983; 112: 424-30.

[15] Huey RB, Stevenson RD. Integrating thermal physiology and ecology of ectotherms: a discussion of approaches. Am Zool 1979; 19: 357-66.

[16] Angilleta MJ, Niewiarowski PH, Navas, CA. The evolution of thermal physiology in ectotherms. J Therm Biol 2002; 27: 249-68.

[17] Wallman HL, Bennett W.A. Effects of parturition and feeding on thermal preference of Atlantic stingray, Dasyatis sabina (Lesueur). Environ Biol Fish 2006; 75: 259-67.

[18] Mottet MG. The fishery biology of sea urchins in the family of the sea urchin Strongylocentridae. Was Dep Fish Tech Rep 1976 20: 166.

[19] Kato S, Schroeter SC. Biology of the red sea urchin Strongylocentrotus franciscanus and its fishery in California. Mar Fish Rev 1985; 47: 1-20.

[20] Hammond LM, Hofmann GE. Thermal tolerance of Strongylocentrotus purpuratus early life history stages: mortality, stress-induced gene expression and biogeographic patterns. Mar Biol 2010; 157: 2677-87.

[21] Palleiro-Nayar JS, Sosa-Nishizaki O, Montaño-Moctezuma G. Impact of substrate and the presence of adults on recruitment of the sea urchin Strongylocentrotus franciscanus en Baja California. Cien Mar 2011; 37: 59-70.

[22] Díaz F, Re AD, Medina Z, Re G, Valdez G, Valenzuela F. Thermal preference and tolerance of green abalone Haliotis fulgens (Philippi, 1845) and pink abalone Haliotis corrugata (Gray, 1828). Aqua Res 2006; 37: 877-84.

[23] Reynolds WW, Casterlin M.E. Behavioral thermoregulation and the final preferendum paradigm. Am Zool 1979; 19: 211-24.

[24] Nelson SG, Simmons MA, Knight AW. Calorigenic effect of diet on the grass shrimp Crangon franciscorum (Crustacea: Crangonidae). Comp Biochem Physiol 1985; 82A: 373-376.

[25] Beamish FWH, Trippel EA. Heat Increment: A static dynamic dimension in bioenergetic models? Trans Am Fish Soc 1990; 119: 649-61.

[26] Zar JH. Biostatistical analysis. Prentice Hall. New Jersey 1999; 663.

[27] Tukey JW. Exploratory data analysis. Adisson-Wesley, Reading, MA 1977; 688.

[28] Kavaliers M. A circadian rhythm of behavioral thermoregulation in a freshwater gastropod, Helisoma trivolis. Can J Zool 1980; 58: 2152-5.

[29] Reynolds WW, Casterlin ME, Millington S.T. Circadian rhythm of preferred temperatures in the bowfish Amia calva, a primitive holostean fish. Comp Biochem Physiol 1978; 60A: 107-9.

[30] Taylor RC. Thermal preference and temporal distribution in three crayfish species. Comp Biochem Physiol 1984; 77A: 513-7. 
[31] Buckle RLF, Díaz-Herrera F, Correa-Sandoval F, Barón-Sevilla B, Hernandez-Rodriguez M. Diel thermoregulation of the crawfish Procambarus clarkii (Crustacea, Cambaridae). J Therm Biol 1994; 19: 419-22.

[32] Brett JR. Energetic responses of salmon to temperature. A study of some thermal relations in the physiology and freshwater ecology of sockeye salmon Orcorhynchus nerka. Am Zool 1971; 11: 99-113.

[33] Leighton DL. Grazing activities of benthic invertebrates in southern California kelp beds. In: North WJ, Ed. The biology of giant kelp beds (Macrocystis) in California, Beiheptezeur Nova Hedwigia 32, Verlag von J. Cramer, Lehre, Germany 1971; pp. 421-53.

[34] McBride SC, Pinnix WD, Lawrence JM, Lawrence AL, Mulligan TM. The effect of temperature on production of gonads by the sea urchin Strongylocentrotus franciscanus fed natural and prepared diets. J World Aqua Soc 1997; 28: 357-65.
[35] Farmanfarmaian A, Giese AC. Thermal tolerance in the western purple sea urchin Strogylocentrotus purpuratus. Physiol Zool 1963; 36: 237-43.

[36] Ulbricht RJ, Pritchard AW. Effect of temperature on the metabolic rate sea urchins. Biol Bull 1972; 142: 178-85.

[37] Kita J, Tsuchida S, Setoguma T. Temperature preference and tolerance, and oxygen consumption of the marbled rock-fish, Sebasticus marmoratus. Mar Biol 1996; 125: 467-71.

[38] Debnath D, Pal AK, Sahu NP, et al. Thermal tolerance and metabolic activity of yellowtail catfish Pangasius pangasius (Hamilton) advanced fingerlings with emphasis on their culture potential. Aquaculture 2006; 258: 606-10

[39] Pearse JS. Ecological role of purple sea urchins. Science 2006; 314: 940-41.

[40] Cameron RA, Schroeter SC. Sea urchin recruitment: Effect of substrate selection on juvenile distribution. Mar Ecol Prog Ser 1980; 2: 243-7.

(C) Salas et al.; Licensee Bentham Open.

This is an open access article licensed under the terms of the Creative Commons Attribution Non-Commercial License (http://creativecommons.org/licenses/ by-nc/3.0/) which permits unrestricted, non-commercial use, distribution and reproduction in any medium, provided the work is properly cited. 